\title{
Integrated online marketing communication: implementation and management
}

\author{
Călin Gurău \\ GSCM-Montpellier Business School, Montpellier, France
}

Integrated online marketing communication

\begin{abstract}
Purpose - The purpose of this paper is to investigate the particularities of integrated marketing communication (IMC) in the online environment.

Design/methodology/approach - Both secondary and primary data (face-to-face interviews with 29 marketing or communication managers of UK online consumer retail firms) are analysed in order to identify the various meanings of the integrated online marketing communication, the opportunities and challenges raised by online communication, and the structure of an efficient integrated online marketing communication system.

Findings - The transparency, interactivity and memory of the internet force the organisation to adopt a proactive-reactive attitude in online communication, and to combine consistency and continuity with flexibility and customisation.

Research limitations/implications - The number of interviews used to collect primary data is relatively small; the use of the information collected is general and unstructured; and the findings are applicable only to online customer product retailers.

Practical implications - The messages sent by the company to its online audiences have to be transformed/adapted in a three-stage process.

Originality/value - The paper identifies the specific opportunities and challenges raised by the internet for integrated marketing communication, and proposes an original model for the adaptation of online messages to core corporate values, communication strategy and tactics, and targeted audience/communication channels.
\end{abstract}

Keywords Integrated marketing communications, Internet, United Kingdom, Online operations

Paper type Research paper

\section{Introduction}

The emergence and the development of integrated marketing communication (IMC) has been determined by a number of evolutionary trends in various areas of marketing - the increased fragmentation and segmentation of markets, relationship marketing and direct marketing (Durkin and Lawlor, 2001; Eagle and Kitchen, 2000); information technology - the development of new communication technologies and database applications (Kitchen and Schultz, 1999; McGoon, 1999; McKim, 2002; Reich, 1998); and communication - increased fragmentation of media audiences, multiplicity and saturation of media channels (Hackley and Kitchen, 1998; Smith, 2002). From this perspective, the new paradigm of IMC can be represented as a strategic answer to the social and business conditions of the postmodern society (Proctor and Kitchen, 2002).

Despite the recognised impact of the internet on integrated marketing communication, very few studies have investigated the specific requirements and opportunities for IMC in the online environment (Durkin and Lawlor, 2001; Reich,

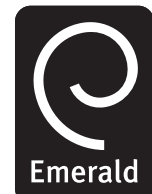

Journal of Communication Management Vol. 12 No. 2, 2008 pp. 169-184 (C) Emerald Group Publishing Limited 1363-254X DOI 10.1108/13632540810881974 
JCOM

12,2

170

1998), and the relation between IMC and customer relationship management (Grönroos, 2004; Johnson and Schultz, 2004; Schultz, 2003).

The present paper attempts to investigate the particularities of implementing IMC in an online environment. The study starts from the premise that the specific characteristics of the internet transform the application of IMC principles from an alternative option to an absolute requirement (Schultz, 1996). Based on an analysis of the specific characteristics of the online environment and audiences, and on the primary data collected through face-to-face interviews with 29 marketing or communication managers of UK consumer retail firms, the meanings of the integrated marketing communication in the online environment, as well as the challenges and the opportunities created by the internet for the implementation of an online IMC process, are identified and discussed. The contrastive elements of the integrated online marketing communication are then synthesised in a theoretical model that can be adopted by internet-active business organisations.

\section{Integrated marketing communication - the evolution of a concept}

The IMC approach has received almost instant recognition at the end of the 1990s, as a result of the existing trends to reduce the budget allocated to mass advertising campaigns and to concentrate on segmented or personalised communication with final consumers (Durkin and Lawlor, 2001; Eagle and Kitchen, 2000). The increased fragmentation of media and customers, as well as the revolution introduced in mass communication by the new communication channels - internet and mobile communication technologies - has created the need for a new approach to marketing communication, that can insure centralised management and a consistency of corporate messages sent towards various audiences (McArthur and Griffin, 1997; Semenik, 2002; Smith, 2002).

A series of articles written between 1991 and 1996 have outlined the specific dimensions of the IMC concept, presenting it as a logical answer to the problems experienced by many business and non-profit organisations (Miller and Rose, 1994; Moriarty, 1994; Novak et al. 1996; Rose, 1996; Schultz, 1991, 1993a, 1993b; 1996). Following this phase in which the concept has received the proper legitimacy, a series of studies (Kitchen and Schultz, 1997; 1998; 1999) have initiated an investigation into the practical application of the concept by the practitioners - especially US and UK-based advertising agencies. The conclusions of these studies were complex: on one hand, the advertising executives recognised the impact of IMC on increasing the effectiveness of creative ideas, providing greater communication consistency, and improving the client return on investment; on the other hand, they outlined the problems related with measuring the IMC outcomes in terms of time and cost efficiencies (Kitchen et al., 2004).

The further development of the IMC theory was a horizontal one, the concept being associated with various areas of corporate communications: management and branding (Fill, 2002), customer and stakeholders relationships (Duncan, 2002), global branding and localised communication (Kanso and Nelson, 2002). At the same time, a series of authors criticised the IMC lack of theoretical foundation (Cornelissen and Lock, 2000), or the real applicability of the concept (Percy et al., 2001).

The concept of IMC was defined in many different, often contradictory, ways (Duncan, 2002; Kitchen, 1999; Kliatchko, 2008; Schultz et al., 1993; Smith et al., 1997; 
Shimp, 2000). The integration of marketing communication procedures was considered a result of centralised management, centralised budgeting, or message similarity across all communication channels.

According to Pickton and Broderick (2001), marketing communications tools that were traditionally separated and specialised in "above the line" and "below-the-line" activities, should be now integrated under the IMC concept. Pickton and Broderick (2001) claim that synergy is the principal benefit of bringing together the various facets of marketing communications in a mutually supportive way. From this perspective, marketing communication decisions should focus on the marketing communications channel that offers the highest benefit for all the stakeholders. The focus of this definition is still very much on communication functions (tactics) rather than on the broad view of establishing close relationships to multiple stakeholders.

Other definitions emphasise that the integration of marketing communication should not be understood as a simple uniformity of the message transmitted across different channels (Kitchen et al., 2004), but rather as the complex coordination and management of the information transmitted though complementary channels in order to effectively present a coherent image of the organisation to the targeted audiences. A good example is the definition proposed by Keegan et al. (1992, p. 631):

Integrated marketing communications is the strategic co-ordination of all messages and media used by an organisation to collectively influence its perceived brand value.

This definition focuses on the concept of "strategic co-ordination", indicating the evolution from tactical coordination towards a more strategic approach, in order to realise communication synergies. In addition, the definition considers "all messages" highlighting that both internal and external activities contribute to marketing communications efforts, and stresses the focus on brand value that requires a change of marketing and communication perspective. At the heart of this definition is the assumption that the credibility and value of both the company and its brand(s) will increase, when messages transmitted to various audiences become consistent across time and targets.

Another definition proposed by Duncan (2002, p. 8) demonstrates the current conceptual perception of IMC:

A cross-functional process for creating and nourishing profitable relationships with customers and other stakeholders by strategically controlling or influencing all messages sent to these groups and encouraging data-driven, purposeful dialogue with them.

An important contribution of this definition is the emphasis on "profitable relationships".

Moreover, Duncan acknowledges that integrated marketing communications involves a cross-functional process. This indicates that all organisational departments that interact with customers and strategic stakeholders must share a common understanding and work collectively to develop long-term brand relationships. Furthermore, the notion of stakeholders implies the shift in the IMC concept from customer target audiences to the inclusion of key stakeholder groups such as employees, investors, suppliers, distributors, media and the social community.

Conceptually, IMC provides an opportunity for organisations to enhance the relationship of their brands with customers and other stakeholders (Beverland and Luxton, 2005). The strategic co-ordination of all marketing and communication tools
Integrated online marketing communication

171 
$\mathrm{JCOM}$

12,2

172 can lead to a consistent brand message directed towards the targeted audiences, using effective media planning. This strategy fosters an ongoing consumer-brand relationship dialogue whilst also generating enhanced consumer appeal.

Despite the recognised importance of implementing integrated marketing communication procedures, the organisational structure of many companies prevents or restricts its effective implementation. In reality, IMC does not fit easily into the organisational structure adopted by most firms. Percy (1997) argues that the theory of IMC, while theoretically pragmatic, ultimately fails because of significant structural barriers to its implementation. The most significant organisation barriers for the implementation of the IMC concept are:

- lack of horizontal communication;

- functional specialisation;

- decentralisation;

- lack of IMC planning and expertise;

- lack of budget;

- lack of database technology;

- corporate culture; and

- fear of change.

These barriers must be assessed and properly understood in order to facilitate IMC implementation within an organisation. However, each corporation has different marketing communications structures already in place and must deal with a distinctive organisational culture that is embodied in an individual organisational design. Consequently, it is impossible to design an implementation model that generally fits all firms. The in-depth analysis of each organisation will provide a specific combination of barriers and possible synergies, that have to taken into account when planning and implementing the IMC concept. On the other hand, more research it is necessary, both at theoretical and at practical level, to refine the definition and the modelisation of IMC, and to identify the best ways of integrating the marketing communication operations in specific corporate environments (Gould, 2004; Schultz and Kitchen, 2000a, b).

\section{Research methodology}

In order to analyse the importance and the role of integrated marketing communication for internet-active organisations, the following research objectives have been formulated:

- To analyse the general impact of internet technology on the marketing communication process and the behaviour of audiences.

- To define the meaning/s of integrated online marketing communication.

- To identify the marketing communication synergies allowed by the internet.

- To identify the challenges raised by the internet for the integrated communication process.

- To design a synthetic model describing the structure and functioning of an integrated online marketing communication system. 
A series of secondary sources of data have been accessed in the first instance, in order to collect general information about the evolution of the IMC concept, internet characteristics, online communication and online audiences.

In the second stage of data collection, a series of semi-structured interviews have been conducted with marketing or communication managers of internet-active UK retailing firms. Using the contact information provided on their web sites, 70 UK retailers specialised in consumer products (food, drinks, cosmetics, clothes, shoes) have been contacted by phone or by email, and invited to participate in this study. 34 of these firms have responded favourably, but only 29 interviews could be organised because of time restrictions in the interviewees' programme. The face-to-face interviews took place during February-May 2005, and lasted between 40 and 60 minutes. The topics of discussion included the concept of integrated marketing communication, the opportunities and challenges created by the internet concerning the corporate communication model, and the specific strategic model that can enhance the online marketing communication process. This methodological approach attempts to implement in practice the recommendation of Kitchen and Schultz (1999) to investigate and analyse the reaction of various practitioners to the IMC concept.

The analysis of the primary data was made manually, considering the limited number of interviews performed and the exploratory nature of the study.

\section{The impact of the internet technology on marketing communication}

The rapid development of the internet in the last ten years has changed the classical communication procedures (Blattberg and Deighton, 1991; Holtz, 1999), because of three specific and co-existent characteristics that differentiate it from any other communication channel:

- Interactivity. The internet offers multiple possibilities of interactive communication, acting not only as an interface, but also as a communication agent (allowing a direct interaction between individuals and software applications).

- Transparency. The information published online can be accessed and viewed by any internet user, unless this information is specifically protected.

- Memory. The web is a channel not only for transmitting information, but also for storing information - in other words, the information published on the web remains in the memory of the network until it is erased.

These options are transforming the profile and the behaviour of online audiences. Marketing communication practitioners should therefore adapt to the new realities of how audiences get and use information:

- The audience is connected to the organisations. The traditional communication channel was uni-directional - the institutions communicated and the audiences consumed the information. Even when communication was considered a two-way process, the institutions had the resources to send information to audiences through a very wide pipeline, while the audiences had only a minuscule pipeline for communicating back to the institutions (Ihator, 2001). Now, the communication channel is a network, not a pipeline. This network has closed the gap between institution and audience. Everybody involved in sending

Integrated online marketing communication

173 
JCOM

12,2

174

the message - the company, its CEO, its communication manager, the external communication agency - are only one click away from the audience. To some extent, communicators have grasped and even embraced this new proximity, fact demonstrated by the vast number of web sites which display "Contact Us" buttons and links (Blattberg and Deighton, 1991). However, in most of the cases, these new facilities are not fully used. The ease of communication has led to an exponential increase in the number of incoming messages, but many organisations have not increased the resources needed to deal with them. In the new model, communicators must engage members of the audience on a one-to-one basis (Holtz, 1999).

- The audience is connected to one another. Considering the nature of the network, if the audience is one click away from the institution, it is also one click away from other members of the audience. Today, a company's activity can be discussed and debated over the internet, without the knowledge of that organisation. In the new environment everybody is a communicator, and the institution is just part of the network (Shankar and Malthouse, 2007).

- The audience has access to other information. In the past, because of the slowness and difficulty to access specific information, the communicator was able to make a statement with the reasonable certainty that it would be impossible for the average audience member to challenge it. Today, it is easy to access multiple sources of information over the internet. Any statement made can be dissected, analysed, discussed and challenged within hours by interested individuals.

- Audiences pull information. The networked world has increased exponentially the number of available channels of communication (Holtz, 1999). Today, we get messages from multiple media channels: email, voice mail, faxes, pagers, cell phones, interoffice memos, overnight courier packages, television (with hundreds of channels), radio, internet radio, etc. As a result, the media that used to provide an efficient channel of communication for practitioners have become now only noise that most of the audiences have learned to filter out. On the other hand, the networked environment provided the audiences with a new model, one in which they no longer accept every message a communicator wants to push to them, but they rather pull the information that suits their interests and needs. In the networked environment, information has to be available where audiences can find it, and must be customized or customizable (Rowley, 2001, 2004).

Therefore, in comparison with the traditional customer, the internet user has more control over the communication process, and can adopt a more proactive attitude, expressed by the capacity to:

- easily search, select and access information (using search and meta-search engines, intelligent agents, etc.);

- contact online organisations or other individuals (using email, chat or discussion forms); and

- express their opinions/views in a visible and lasting manner (creating and storing online content). 
Taking advantage of the various online resources requires strategic thinking that recognizes that all these aspects of the networked world coexist. They must be coordinated to achieve specific, measurable objectives consistent with the goals of any marketing communication effort.

\section{The meaning/s of integrated online marketing communication}

Many studies have emphasised the lack of a unifying definition for integrated marketing communication. One possible explanation of this theoretical crisis is the multitude of possible co-existent meanings for the IMC concept (Lee and Park, 2007). This assumption might also be true in the case of internet communication.

In order to identify the meaning/s of integrated online marketing communication, the interviewees have been asked to freely express the issues related with this concept in their practical activity. The responses have been semantically analysed and the following categories of meaning have been identified (see Table I).

As it can be seen, for all respondents, the integrated online marketing communication represents a multi-faceted phenomenon, which comprises issues related with the message, the communication function, the management of information, and the specific mix of channels used for corporate communication. On the basis of these answers, the synergies and the challenges raised by the internet are discussed in more detail in the following two sections.

\section{Internet-based communication synergies}

Internet technologies allow online-active organisations to implement three main communication synergies:

(1) The integration and coordination of communication modes (Hoffman et al., 1995): the organisations can combine one-to-one (email), one-to-many (list-based email messages, web pages), and many-to-many (discussion forums) communication in the online environment. This synergy increases

\begin{tabular}{lcc}
\hline Meaning & Frequency & Percentage \\
\hline $\begin{array}{l}\text { Combination of communication modes (one-to-one, one-to-many, } \\
\text { many-to-many) }\end{array}$ & 29 & 100 \\
$\begin{array}{l}\text { Integration of information types (text, sound, image) } \\
\begin{array}{l}\text { Consistency of messages transmitted trough the online } \\
\text { communication-mix (coherent meaning) }\end{array}\end{array}$ & 27 & 93.1 \\
$\begin{array}{l}\text { Integration of marketing and PR communication functions in } \\
\text { the messages provided online }\end{array}$ & 29 & 100 \\
$\begin{array}{l}\text { The coordination of the process: message conception - } \\
\text { transmission - feedback reception and analysis, in a closed loop }\end{array}$ & 17 & 58.6 \\
$\begin{array}{l}\text { The direct connection of the corporate information system with } \\
\text { the internet }\end{array}$ & 18 & 62 \\
$\begin{array}{l}\text { Coordination of internal, external and internal-external flows of } \\
\text { information }\end{array}$ & 19 & 65.5 \\
$\begin{array}{l}\text { The integration of online marketing communication with the } \\
\text { communication conducted through traditional channels } \\
\begin{array}{l}\text { The consistency of the corporate message at } \\
\text { global/international level }\end{array}\end{array}$ & 24 & 82.8 \\
\hline
\end{tabular}

\section{Integrated online marketing communication}

175 
$\mathrm{JCOM}$

12,2

\section{6}

the flexibility of the integrated communication approach, providing opportunities both for the personalisation and integration of messages (Rowley, 2001, 2004). One respondent has outlined that:

... the corporate web site represents a common platform for various communication tools and procedures. This represents both an opportunity and a challenge for integrated marketing communication. On one hand, this is forcing us to consider the interaction and the synergy among various communication procedures, but on the other hand, creates problems in terms of segmenting and addressing the needs of various audiences.

(2) The integration and coordination of various types of information (Azzone et al., 2000): the recent advances in information and communication technologies (broadband) allow organisations to transmit or receive a complex combination of information in the form of texts, sounds and images (static and/or dynamic). This synergy has a direct effect on the complexity and clarity of the communication, enhancing the capacity of the organisation to tailor its messages to the specific needs and requirements of various audiences (Vescovi, 2000). Unfortunately, complex messages can often create compatibility problems. One respondent indicated that: "after launching this marketing communication campaign, we had many clients complaining that they cannot view the clip on their computer". In other cases, online customers may consider online communication tools as intrusive: "we were obliged to eliminate the pop-up windows from our online communication mix, because clients considered them too aggressive."

(3) The integration and coordination of complex information flows between the organisational intranet and the internet. The organisation is now able to implement advanced software applications that connect its marketing and management information systems with the online environment, and to automatically coordinate the communication with various audiences (Basu et al., 2000). This capability has a powerful impact on multiple aspects of the communication process:

(4) the capacity to automatically capture and register customer data (demographic or behavioural) and customer feed-back;

(5) the capacity to automatically analyse the information collected about audiences, to a level of segmentation and detail that allows the implementation of one-to-one marketing communication; and

(6) the capacity to use the existing databases in order to automatically launch and coordinate highly targeted communication campaigns (automatic email responses, automatic email campaigns, personalised event marketing, promotional news and newsletters).

Some retail organisations track the interaction between the online user and their web site: "the time spent by a client on a specific web page can represent an indication of his/her present interest". "We use the results provided by our online behaviour tracking system to create personalised promotions targeted to individual customers". 
Internet-based communication challenges

The online environment creates not only opportunities, but also challenges for the marketing communication process. The transparency of the web makes online information available to all audiences, and reinforces the need for consistency in the planning, design, implementation and control of online marketing communication (Hart et al., 2000).

On the other hand, since they are sharing the same channel and audiences, the marketing and PR messages published on organisational web sites are becoming more integrated (Ashcroft and Hoey, 2001). The corporate web site is usually structured on various information categories, such as: organisational profile, activity, products and services, financial reports and other information for investors, job vacancies, contact, and related links. A previous study of online communication in the UK biotechnology sector has identified the tendency of these online information categories to share both Marketing and PR communication functions, although for each category there is usually a primary and a secondary communication function (Ranchhod et al., 2002). This tendency is in line with the predictions made by Kotler and Mindak (1978) concerning the progressive integration of marketing and PR communication, and reinforces the application of the integrated marketing communication concept.

The variety and multiplicity of information, sources, and interpretations available online raises an important challenge related with the management of the corporate image and identity. The voice of the corporation cannot be considered anymore as the dominant message, but only as a component in a mosaic of communication activities. The construction of the online corporate identity needs to strike a balance between proactivity and reactivity, continuity and flexibility. The meaning is not simply transmitted, but has to be negotiated separately with each online audience. The message needs to be adapted to the specific level of understanding and interpretation of each public, but, on the other hand, has to express the same core organisational values, in order to display a coherent organisational image (Grönroos, 2004). The various competing messages transmitted by other organisations, pressure groups, governmental agencies, or individuals have to be taken into account and accommodated in such a way as the resultant effect to be favourable for the company (Hoey, 1998). One respondent outlined that:

... on the internet, the customer can easily access various sources of information about the same product and event. The main challenge is how to increase and maintain the credibility of your own communication among all these competing sources.

The international dimension of the internet creates another specific problem for communication practitioners. Complex choices have to be made and implemented in terms of the communication strategy and tactics. If the company attempts to reach foreign audiences, the message needs to be adapted to the cultural specificity of the overseas public. This raises important questions regarding the possibility of integrated online marketing communication in the global context: "we often communicate with customers from various cultural and economic backgrounds. In these conditions we must apply a clear segmentation and positioning strategy, in order to match the needs of every cultural group with our marketing messages."

The specific characteristics of the internet therefore create two conflicting tendencies:
Integrated online marketing communication

177 
$\mathrm{JCOM}$

12,2

178

(1) the fragmentation of audiences and communication contexts requires the customisation of online marketing messages; but

(2) the interactivity, transparency and memory of the web necessitates the consistency of communication and the coherence of the transmitted meaning.

A new strategic model has to be adopted by any organisation that attempts to present a coherent corporate identity in the online environment. The integrated marketing communication is the primary instrument to achieve this objective. However, the implementation of the IMC concept will have to accommodate the specific characteristics of the internet, using the technological capabilities of the new medium to solve the specific challenges raised by the online environment and audiences.

\section{A model for implementing integrated online marketing communication}

Based on the analysis of the specific characteristics of the online environment, applications, and audiences, a tentative model of integrated online marketing communication is proposed in this study. The model was designed and then refined as a result of the direct interaction and debate with 29 marketing or communication managers directly responsible for the online communication strategy of their companies.

The messages send by the company to its online audiences have to be transformed/adapted in a three-stage process. First, the message should respect and integrate the core corporate values of the organisation. Second, the message has to be adapted in relation to the strategic and tactical objectives pursued through the online communication campaign. Third, the message should be transformed considering the specific characteristics of the targeted audience/channel. In the case of online communication, although the internet can be considered as the main channel of communication, there are, in fact, various online applications or modalities of communication that can be combined and used as an online communication-mix (email, chat, web site, discussion forums, etc.). The online communication channels vary in terms of their degree of transparency, interactivity, memory and selectivity, and these dimensions should be taken into account when establishing the proper communication mix for each targeted audience.

This process of message adaptation will preserve a flexible balance between continuity and customisation, the consistency of the adapted communication being determined by the integration of the corporate core values in the structure of each message.

The respondents have also confirmed the tendency to integrate marketing and PR communication functions in the messages transmitted online, although there have been different opinions regarding the intensity of this integration (see Figure 1).

On the other hand, the interactive dimension of the internet forces the firm to adopt a more proactive attitude in searching, registering, and analysing the direct and the indirect feed-back transmitted by the targeted audiences - or even, in some cases, by all categories of relevant audiences connected to the internet (considering the transparency and the memory of the internet, even un-targeted audiences can read and react to some of the online corporate messages). 


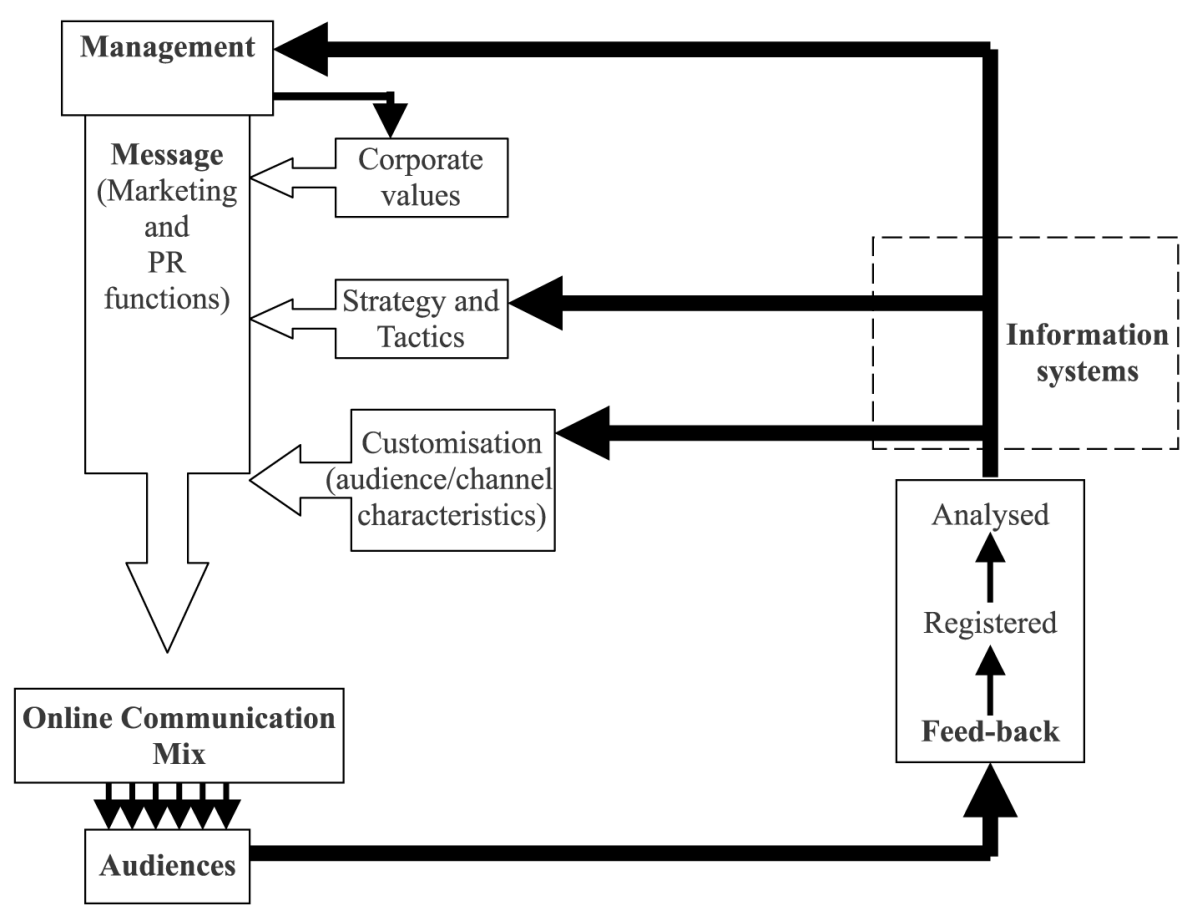

Integrated online marketing communication 179

Figure 1.

The model of integrated online marketing communication

The use of the feed-back information collected and analysed by the firm should represent a highly reactive process. The online environment is very dynamic and any delay of an appropriate reaction to the messages sent by audiences can represent missed opportunities or aggravated situations. The company should therefore use the conclusions of the feed-back analysis in order to define and better refine the strategic objectives of its communication campaigns, and the customisation of messages to audience/channel characteristics.

The feed-back analysis is also transmitted to the company management, that can decide, if necessary, to modify the corporate core values in order to respond better to market requirements. However, this change should not be very frequent, in order to preserve the long-term coherence of corporate communication in line with the desired corporate image.

The respondents also emphasised the importance of an efficient information system, that collects, selects, registers and analyse online input (feed-back), and then acts directly on the adaptation of corporate communication strategy and tactics, as well as on the customisation of online messages (Basu et al., 2000). In some cases, campaign management applications can automatically use the feed-back received for a more effective online message customisation.

On the other hand, the corporate information system represents the necessary basis for enhancing the customer relationship management capabilities of the firm (Grönroos, 2004; McKim, 2002). The level of detail of customer-related data stored and analysed by the internal information system defines the level of personalisation that can be applied by the firm in its online communication and marketing campaigns. In 
$\mathrm{JCOM}$

12,2

180 fact, the modern database and campaign management applications permit the implementation of effective one-to-one marketing communication in the online environment (Granger and Schroeder, 1996).

Figure 2 presents the place of integrated online marketing communication in the online CRM process of the firm. The customer data/feed-back collected online is used directly to better design and implement the online integrated marketing communication, which are then targeting selected online audiences. Correctly implemented, the IMC program is a continuous cycle of gathering data and implementing response-generating marketing communication which is based on previously gathered consumer data (Schultz et al. 1993). An effective flow of continuous information between these three components of the online CRM process can determine increased transaction value and satisfaction both for customers and for organisations (Grönroos, 2004).

\section{Conclusions}

This exploratory study has attempted to identify the major changes determined by the development of internet technology in the area of marketing communication. The online environment raises a series of opportunities and challenges for communication practitioners. The audiences become more fragmented and proactive, but, on the other hand, the company has the possibility to combine various modes and categories of information in a complex message. Online applications also permit the enterprise to collect, register, analyse and use customer data and feed-back for better targeting online audiences and customising its messages.

In fact, the specific characteristics of the internet are making the implementation of integrated online marketing communication both inevitable and efficient for an online organisation. The transparency, interactivity and memory of the internet force the organisation to adopt a proactive-reactive attitude in online communication, and to combine consistency and continuity with flexibility and customisation.

These characteristics can be integrated by designing and implementing a specific model of integrated online marketing communication. The message communicated
Figure 2.

The place of online integrated communication in the online CRM process

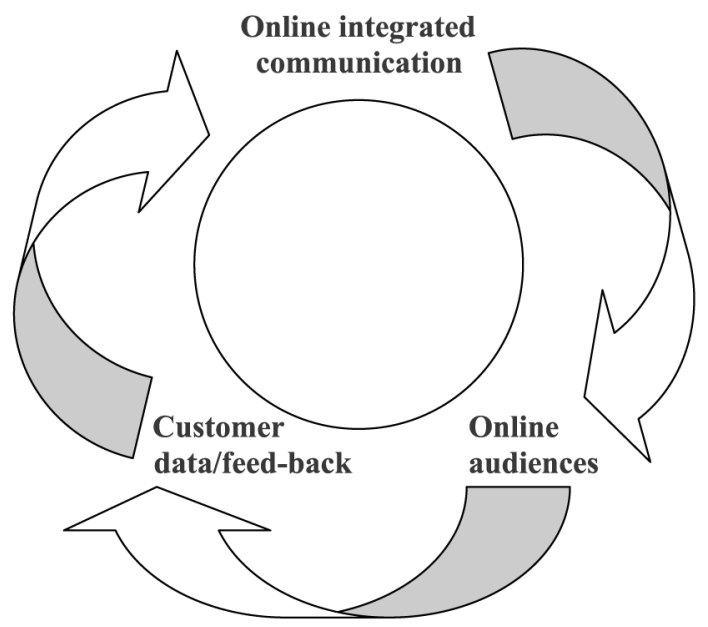


online should be first infused with the core corporate values, then adapted to the online strategy and tactics of the organisation, and finally customised for a specific combination of target audience/online channel. The selection of the appropriate communication-mix needs to take into account the characteristics of the targeted audiences, but also the degree of transparency, interactivity, memory and selectivity of each online channel.

The use of advanced online applications to collect customer data and feed-back information is paramount for the success of the online communication campaign (O'Malley and Mitussis, 2002). Because of the high interactivity of the internet, the communication process has become a real-time dialogue (Grönroos, 2004), that forces the company to quickly analyse the response of the audience to its messages, and to restructure dynamically its communication to the new circumstantial situation. The internal information system has to manage all the relevant flows of information between the online environment and the organisation. Taking into account the feed-back received from internet audiences, automatic software applications can modify the online strategy and tactics of the firm and/or better adapt the message to the reaction and circumstances of the audience. A well-organised information system can also transmit the analysis of the online communication process to the top management, which can take the relevant decisions regarding the core values of the corporation and the general strategy of the firm.

The paper has a number of empirical limitations, determined by its exploratory approach. The number of interviews used to collect primary data is relatively small, and the use of the information collected is general and unstructured, in order to identify and define the main characteristics of an integrated online marketing communication system. The enterprises selected for interviews were only customer products retailers, and therefore the applicability of the identified model might be limited to this category of companies. On the other hand, on the basis of this theoretical model, future studies can investigate the application of the integrated marketing communication concept in other areas of online business, in order to identify possible similarities or differences.

Important issues relevant for the implementation of integrated online marketing communication have not been addressed because of space and methodology limitations. These areas can represent the subject of future research projects investigating: the management process of integrated online marketing communication; the criteria used for selecting and combing various channels in the online communication mix; the relation between the organisation and web advertising agencies; or the challenges raised by the general integration and co-ordination of online and offline (traditional) communication.

\section{References}

Ashcroft, L. and Hoey, C. (2001), "PR, marketing and the internet: implications for information professionals", Library Management, Vol. 22 No. 1, pp. 68-74.

Azzone, G., Bianchi, R. and Noci, G. (2000), “The company's web site: different configurations, evolutionary path", Management Decision, Vol. 38 No. 7, pp. 470-9.

Basu, C., Poindexter, S., Drosen, J. and Addo, T. (2000), "Diffusion of executive information systems in organizations and the shift to web technologies", Industrial Management \& Data Systems, Vol. 100 No. 6, pp. 271-6.

\section{Integrated online marketing communication}

181 
$\mathrm{JCOM}$

12,2

182

Beverland, M. and Luxton, S. (2005), "Managing integrated marketing communication (IMC) through strategic decoupling: how luxury wine firms retain brand leadership while appearing to be wedded to the past”, Journal of Advertising, Vol. 34 No. 4, pp. 1-15.

Blattberg, R.C. and Deighton, J. (1991), "Interactive marketing: exploiting the age of addressability”, Sloan Management Review, Vol. 33 No. 1, pp. 5-14.

Cornelissen, J.P. and Lock, A.R. (2000), "Theoretical concept or management fashion? Examining the significance of IMC", Journal of Advertising Research, Vol. 40 No. 5, pp. 7-15.

Duncan, T. (2002), IMC: Using Advertising and Promotion to Build Brands, McGraw-Hill, New York, NY.

Durkin, M. and Lawlor, M.-A. (2001), "The implications of the internet on the advertising agency-client relationship", The Services Industries Journal, Vol. 21 No. 2, pp. 175-90.

Eagle, L. and Kitchen, P.J. (2000), "IMC, brand communications, and corporate cultures", European Journal of Marketing, Vol. 34 No. 5, pp. 667-86.

Fill, C. (2002), Marketing Communications: Contexts, Strategies and Applications, 3rd ed., Prentice-Hall, London.

Gould, S.J. (2004), "IMC as theory and as a poststructural set of practices and discourses: a continuously evolving paradigm shift", Journal of Advertising Research, Vol. 44 No. 1, pp. 66-71.

Granger, M.J. and Schroeder, D.L. (1996), "Integrating the internet into the business environment", Internet Research: Electronic Networking Applications and Policy, Vol. 6 No. 2, pp. 85-9.

Grönroos, C. (2004), "The relationship marketing process: communication, interaction, dialogue, value”, Journal of Business and Industrial Marketing, Vol. 19 No. 2, pp. 99-113.

Hackley, C. and Kitchen, P.J. (1998), "IMC: A consumer psychological perspective”, Marketing Intelligence \& Planning, Vol. 16 No. 3, pp. 229-35.

Hart, C., Neil, D. and Ellis-Chadwick, F. (2000), "Retailer adoption of the internet - implications for retail marketing", European Journal of Marketing, Vol. 34 No. 8, pp. 954-74.

Hoey, C. (1998), "Maximising the effectiveness of web-based marketing communications", Marketing Intelligence \& Planning, Vol. 16 No. 1, pp. 31-7.

Hoffman, D.L., Novak, T.P. and Chatterjee, P. (1995), "Business scenarios for the web: opportunities and challenges", Journal of Computer-Mediated Communication, Vol. 1 No. 3, available at: www.usc.edu/dept/annenberg/vol1/issue3/vollno3.html

Holtz, S. (1999), Public Relations on the Net, Amacom, New York, NY.

Ihator, A.S. (2001), "Communication style in the information age", Corporate Communications: An International Journal, Vol. 6 No. 4, pp. 199-204.

Johnson, C.R. and Schultz, D.E. (2004), “A focus on customers”, Marketing Management, Vol. 13 No. 5, pp. 20-7.

Kanso, A. and Nelson, R.A. (2002), "Advertising localisation overshadows standardisation", Journal of Advertising Research, Vol. 42 No. 1, pp. 79-89.

Keegan, W., Moriarty, S. and Duncan, T. (1992), Marketing, Prentice-Hall, Englewood Cliffs, NJ.

Kitchen, P.J. (1999), Marketing Communications: Principles and Practice, International Thomson Business Press, London.

Kitchen, P.J. and Schultz, D.E. (1997), "Integrated marketing communications in US advertising agencies: an exploratory study”, Journal of Advertising Research, Vol. 37 No. 5, pp. 7-18.

Kitchen, P.J. and Schultz, D.E. (1998), "IMC - a UK ad's agency perspective", Journal of Marketing Management, Vol. 14 No. 2, pp. 465-85. 
Kitchen, P.J. and Schultz, D.E. (1999), "A multi-country comparison of the drive for IMC", Journal of Advertising Research, Vol. 39 No. 1, pp. 21-38.

Kitchen, P.J., Brignell, J., Li, T. and Jones, G.S. (2004), "The emergence of IMC: a theoretical perspective", Journal of Advertising Research, Vol. 44 No. 1, pp. 19-31.

Kliatchko, J.G. (2008), "Revisiting the IMC construct", International Journal of Advertising, Vol. 27 No. 1, pp. 133-60.

Kotler, P. and Mindak, W. (1978), "Marketing and public relations: should they be partners or rivals", Journal of Marketing, Vol. 42 No. 10, pp. 13-20.

Lee, D.H. and Park, C.W. (2007), "Conceptualisation and measurement of multidimensionality of integrated marketing communications”, Journal of Advertising Research, Vol. 47 No. 3, pp. 222-36.

McArthur, D. and Griffin, T. (1997), "A marketing management view of integrated marketing communications", Journal of Advertising Research, Vol. 37 No. 5, pp. 19-27.

McGoon, C. (1999), "Cutting-edge companies use integrated marketing communication", Communication World, Vol. 16 No. 1, pp. 15-19.

McKim, B. (2002), "The difference between CRM and database marketing”, Journal of Database Marketing, Vol. 9 No. 4, pp. 371-5.

Miller, D.A. and Rose, P.B. (1994), "Integrated communications: a look at reality", Public Relations Quarterly, Vol. 39 No. 1, p. 13.

Moriarty, S.E. (1994), "PR and IMC: the benefits of integration", Public Relations Quarterly, Vol. 39 No. 3, p. 38.

Novak, G.J., Cameron, G.T. and Delorme, D. (1996), "Beyond the world of packaged goods: assessing the relevance of integrated marketing communications for retail and consumer service marketing", Journal of Marketing Communications, Vol. 2 No. 1, pp. 173-90.

O’Malley, L. and Mitussis, D. (2002), "Relationships and technology: strategic implications", Journal of Strategic Marketing, Vol. 10 No. 3, pp. 225-38.

Percy, L. (1997), Strategies for Implementing Integrated Marketing Communication, NTC Business Books, Chicago, IL.

Percy, L., Rossiter, J.R. and Elliott, R. (2001), Strategic Advertising Management, Oxford University Press, New York, NY.

Pickton, D. and Broderick, A. (2001), Integrated Marketing Communications, Pearson Education, Harlow.

Proctor, T. and Kitchen, P.J. (2002), "Communication in postmodern integrated marketing", Corporate Communications: An International Journal, Vol. 7 No. 3, pp. 144-54.

Ranchhod, A., Gurău, C. and Lace, J. (2002), "On-line messages: developing an integrated communications model for biotechnology companies", Qualitative Market Research: An International Journal, Vol. 5 No. 1, pp. 6-18.

Reich, K. (1998), "IMC: through the looking glass of the new millennium", Communication World, Vol. 15 No. 9, pp. 26-8.

Rose, P.B. (1996), "Practitioner opinions and interests regarding integrated marketing communications in selected Latin American countries", Journal of Marketing Communications, Vol. 2 No. 1, pp. 125-39.

Rowley, J. (2001), "Remodelling marketing communications in an internet environment", Internet Research: Electronic Networking Applications and Policy, Vol. 11 No. 3, pp. 203-12.

Rowley, J. (2004), "Just another channel? Marketing communications in e-business", Marketing Intelligence and Planning, Vol. 22 No. 1, pp. 24-41.

\section{Integrated online marketing communication}

183 
$\mathrm{JCOM}$

12,2

184

Schultz, D.E. (1991), "Integrated marketing communications: the status of integrated marketing communications programs in the US today", Journal of Promotion Management, Vol. 1 No. 1, pp. 99-104.

Schultz, D.E. (1993a), "Integrated marketing communications: maybe definition is in the point of view”, Marketing News, Vol. 27 No. 1, p. 17.

Schultz, D.E. (1993b), "We simply can’t afford to go back to mass marketing”, Marketing News, Vol. 27 No. 4, p. 20.

Schultz, D.E. (1996), "The inevitability of integrated communications", Journal of Business Research, Vol. 37 No. 3, pp. 139-47.

Schultz, D.E. (2003), "Opinion piece: the next generation of integrated marketing communication”, Interactive Marketing, Vol. 4 No. 4, pp. 318-9.

Schultz, D.E. and Kitchen, P.J. (2000a), "A response to 'Theoretical concept or management fashion?”, Journal of Advertising Research, Vol. 40 No. 5, pp. 17-21.

Schultz, D.E. and Kitchen, P.J. (2000b), Communicating Globally: An Integrated Marketing Approach, Macmillan Press, London.

Schultz, D.E., Tannenbaum, S.I. and Lauterborn, R.F. (1993), Integrated Marketing Communication: Putting it Together and Making it Work, NTC Business Books, Lincolnwood, IL.

Semenik, R.J. (2002), Promotion and Integrated Marketing Communications, Thomson Learning, Cincinnati, $\mathrm{OH}$.

Shankar, V. and Malthouse, E.C. (2007), "The growth of interactions and dialogs in interactive marketing", Journal of Interactive Marketing, Vol. 21 No. 2, pp. 2-4.

Shimp, T.A. (2000), Advertising Promotion: Supplemental Aspects of Integrated Marketing Communications, 5th ed., The Dryden Press, Fort Worth, TX.

Smith, P.R. (2002), Marketing Communications: An Integrated Approach, 3rd ed., Kogan Page, London.

Smith, P.R., Berry, C. and Pulford, A. (1997), Strategic Marketing Communications: New Ways to Build and Integrate Communication, Kogan Page, London.

Vescovi, T. (2000), "Internet communication: the Italian SME case", Corporate Communications: An International Journal, Vol. 5 No. 2, pp. 107-12.

\section{Further reading}

Cornelissen, J.P. and Lock, A.R. (2001), "The appeal of integration: managing communications in modern organisations”, Marketing Intelligence \& Planning, Vol. 19 No. 6, pp. 424-31.

\section{Corresponding author}

Călin Gurău can be contacted at: calin.gurau@wanadoo.fr

To purchase reprints of this article please e-mail: reprints@emeraldinsight.com Or visit our web site for further details: www.emeraldinsight.com/reprints 
Reproduced with permission of the copyright owner. Further reproduction prohibited without permission. 